\title{
Cytokine serum levels in patients infected by human immunodeficiency virus with and without Trypanosoma cruzi coinfection
}

\author{
Níveis séricos de citocinas em pacientes infectados pelo vírus da \\ imunodeficiência humana com e sem coinfecção pelo Trypanosoma cruzi
}

\author{
Denise Bertulucci Rocha Rodrigues ${ }^{1,2}$, Dalmo Correia ${ }^{1}$, Mônica Dias Marra ${ }^{1}$, \\ Luis Eduardo Ramirez Giraldo ${ }^{1}$, Eliane Lages-Silva ${ }^{1}$, Mario León Silva-Vergara ${ }^{1}$, \\ Cristina Hueb Barata ${ }^{1}$ and Virmondes Rodrigues Junior ${ }^{1}$
}

\begin{abstract}
This study assessed the number of CD4 T lymphocytes, the parasitemia and serum levels of interferon gamma (IFN- $\gamma$ ), tumor necrosis factor alpha (TNF- $\alpha$ ), interleukin-1 (IL-1), IL-4 and IL-10 of patients infected by human immunodeficiency virus (HIV) and human immunodeficiency virus/Chagas' disease coinfection. CD4 T lymphocytes were low in the two groups of patients, although significantly lower in patients without Chagas' disease. Serum levels of IFN- $\gamma$, IL-4 and TNF- $\alpha$ were significantly higher in patients with HIV/Chagas' disease. IL-4/IFN- $\gamma$ ratios were higher in patients with HIV/Chagas' disease, which showed a clear balance in favor of Th2-like cytokines in this group of patients. This Th2 balance was higher in patients with detectable parasitemia. We conclude that, although immunosuppression was observed, with CD4 T lymphocytes bellow 200/ $\mathrm{mm}^{3}$, these patients did not display reactivation of $\mathrm{T}$. cruzi infection and that a balance favorable to Th2 was associated with the presence of parasitemia.
\end{abstract}

Key-words: Cytokine. Chagas' disease. Acquired immunodeficiency syndrome. Trypanosoma cruzi.

\section{RESUMO}

Neste estudo foi avaliado o número de linfócitos TCD4, a parasitemia e os níveis séricos de interferon gama (IFN- $\gamma$ ), fator de necrose tumoral alfa (TNF- $\alpha$ ), interleucina-1 (IL-1), IL-4 e IL-10 em pacientes infectados pelo vírus da imunodeficiência adquirida ou apresentavam co-infecção pelo HIV/Trypanosoma cruzi. O número de linfócitos T CD4 estava baixo nos dois grupos de pacientes, embora significativamente menor nos pacientes sem a doença de Chagas. Os níveis séricos de IFN- $\gamma$, IL-4 e TNF- $\alpha$ foram significativamente maiores nos pacientes com a co-infecção pelo HIV/Trypanosoma cruzi. A razão IL-4/IFN- $\gamma$ foi maior nos pacientes com a co-infecção pelo HIV/T. cruzi, que sugere um balanço favorável para perfil Th2 nesse grupo de pacientes. Este balanço Th2 foi maior nos pacientes com parasitemia detectável. Conclui-se que, embora tenha sido observado imunossupressão, na maioria com linfócitos T CD 4 abaixo de $200 / \mu \mathrm{m}^{3}$, esses pacientes não reativaram a infecção pelo T. cruzi e que o balanço favorável a Th2 estava associado à presença de parasitemia.

Palavras-chaves: Citocinas. Doença de Chagas. Síndrome da imunodeficiência adquirida. Trypanosoma cruzi.

In spite of the considerable increase in knowledge and the use of control measures, acquired immunodeficiency syndrome (AIDS) is still the fifth leading cause of death in the world ${ }^{14}$. In Latin America, Brazil has the highest number of cases despite the use of highly active antiretroviral therapy (HAART), which has been shown to be very effective ${ }^{16}$. Due to the increase of the HIV epidemic and the migration of patients from rural areas to urban centers, the probability of coinfection with HIV and Trypanosoma cruzi has increased.

Immunodeficiency interferes with the host defenses and alters the clinical course of the disease. The relationship between immunosuppression caused by the human

\footnotetext{
1. Universidade Federal do Triângulo Mineiro, Uberaba, MG. 2. Universidade de Uberaba, Uberaba, MG.

Supported by FAPEMIG and CNPq. M.D.Marra was a fellow of CNPq/PIBIC

Address to: Prof. Virmondes Rodrigues Junior. Disciplina de Imunologia/UFTM. Rua Frei Paulino 30, 38025-180 Uberaba, MG, Brasil.

Tel: 5534 3318-5289, Fax: 553433185651

e-mail: vrodrigues@mednet.com.br

Recebido para publicação em 18/5/2005

Aceito em 22/8/2005
} 
immunodeficiency virus (HIV) and the occurrence of opportunistic infections is well documented in the literature, due to reactivation of endemic parasite infections such as leishmaniasis and Chagas' disease $\mathrm{e}^{41415}$.

HIV/T. cruzi coinfection may lead to clinical reactivation of Chagas' disease, which is manifested mainly as severe acute meningoencephalitis, where a great number of parasites can easily be detected in peripheral blood and cerebrospinal fluid 56781019 . Factors involved in the reactivation are not well understood. Nevertheless, clinical observations suggest that the reduction of the number of CD4 T lymphocyte, usually to levels below 200 cells $/ \mu \mathrm{m}^{3}$, may be important. Recently, the reactivation of Chagas' disease in patients with AIDS, especially those who have a compromised central nerve system (CNS), has been attributed to the subpopulation of neurotropic strains of Trypanosoma cruzi ${ }^{13}{ }^{15}$. On the other hand, in HIV/ leishmaniasis coinfection, it has been proposed that the mechanism of reactivation involves high viral replication and production of Th2 cytokines ${ }^{17}$.

Although some data has been recently added to our knowledge of T. cruzi/HIV coinfection, the level of immunological impairment that may lead to Chagas' disease reactivation has yet to be clarified. To this end we analyzed the number of CD4 T lymphocytes and the serum levels of IFN- $\gamma$ and TNF- $\alpha$, as a prototype of Th1 cytokine, involved in the activation of anti- $T$ cruzi effector mediator and IL- 4 and IL-10, as prototypes of Th2 cytokines, possibly involved in mechanisms of parasite survival.

In this study, we analyzed the parasitemia, the number of CD4 T lymphocytes and the cytokine serum levels in patients with HIV/T. cruzi coinfection in comparison with HIV infected. Our results point to a favorable Th2 balance associated with HIV/T. cruzi coinfection.

\section{MATERIAL AND METHODS}

Patients. Twenty-eight HIV infected individuals were studied. Case definition for HIV/AIDS was done according to the criteria defined by the Center of Disease Control and Prevention - Atlanta, USA (CDC). Ages varied from 21 to 58 years. Among them, 18 were men. From this total, 18 were positive serologically for Chagas' disease (HIV/T. cruzi coinfection) and the other 10 patients did not have circulating antibodies to T. cruzi and were asymptomatic at the time of blood collection (HIV). These patients received medical assistance at the Infectology Service of the 'Faculdade de Medicina do Triângulo Mineiro', MG, Brazil and were not using HAART at the time of blood collection. This protocol was approved by the institutional review board. Four $\mathrm{ml}$ of blood were collected from each volunteering patient in presence of EDTA.

Determination of CD4 T lymphocytes. The number of CD4 T lymphocytes was determined by flow cytometry. For this, $100 \mathrm{ml}$ of collected blood with EDTA was incubated with $10 \mu \mathrm{l}$ of FITC conjugate anti-CD 4 monoclonal antibody (Pharmingen, San Diego, CA, US) and PE anti-CD3 monoclonal antibody (Pharmingen) for $30 \mathrm{~min}$ at room temperature. After this period, the red blood cells were lyzed and leucocytes were washed with PBS and fixed with PBS containing $2 \%$ of paraformaldehyde. The number of CD4 T lymphocytes was determined in a FACScalibur cytometer (Becton Dickson; San Diego, CA, US). The results were expressed as the number of $\mathrm{CD} 4+$ cells per micro liter of blood.

Evaluation of parasitemia. To detect circulating parasites in the blood of patients, xenodiagnosis and hemoculture were performed simultaneously. Hemoculture was done according to methods previously described ${ }^{3}$. Thirty $\mathrm{ml}$ of blood was centrifuged at $4^{\circ} \mathrm{C}$ to remove the plasma. The pelleted cells were washed by centrifugation at $4^{\circ} \mathrm{C}$ in liver infusion tryptose medium. The concentrated erythrocytes were resuspended in $30 \mathrm{ml}$ of liver infusion tryptose and uniformly distributed in six test tubes. Cultures were maintained at $28^{\circ} \mathrm{C}$ and homogenized weekly. Microscopic examination was done on days 30,60, and 90 by analyzing $10 \mu l$ from each tube. Each xenodiagnosis was performed with 40 third-stage nymphs of Triatoma infestans that were placed on the patients' forearms for a 30 min feeding period. Insects were individually examined for Trypanosoma cruzi in the feces by abdominal compression, and the content was examined by light microscopy on days 30 and 60 after feeding.

Cytokine titration. For cytokine titration, 96 microwell plates (Nunc, Roskilde, Denmark) were sensitized overnight with anti-IL-1 $\beta$ mAb (Genzyme, Cambridge, MA, US), anti TNF- $\alpha$ (Genzyme), anti-IL-4 (Mabtech,Nacka, Sweden), anti-IL-10 mAb (Pharmingen), or anti-IFN- $\gamma$ mAb (Mabtech). Nonspecific binding was prevented by incubating the plates with 3\% BSA (Sigma, Saint Louis, MA, US) in PBS for 4 hours. Later, plates were incubated overnight with 100 $\mu$ l of 1:2 dilution of patient's serum in PBS and 2\% BSA. Controls were run with standard cytokines (Pharmingen and R\&D, Minneapolis, MN, USA). Plates were then washed four times with PBS 0.05\% Tween 20 and incubated with rabbit anti-IL-1 $\beta$ Ab (Genzyme); rabbit anti TNF- $\alpha$ Ab (Genzyme); biotinylated anti-IL-4 mAb (Mabtech); biotinylated anti IL-10 mAb (Pharmingen), or biotinylated antiIFN- $\gamma$ mAb (Mabtec) for 4h. Afterwards, plates were washed with PBS Tween and incubated for $2 \mathrm{~h}$ with alkaline phosphatase conjugated goat anti-rabbit IgG (Pearce, US) or phosphatase alkaline conjugated to streptavidin. Finally, plates were washed four times and enzymatic activity was developed by incubating the plates with p-nitrophenyl phosphate (Sigma). Absorbance was read at $405 \mathrm{~nm}$ in a microplate reader (Biorad, Hercules, CA, US). The sensitivity of the tests was $10-30 \mathrm{pg} / \mathrm{ml}$.

Statistical analysis. Differences in cytokine levels between patient groups were analyzed by Mann-Whitney test with significance set at $\mathrm{p}<0.05$. The Th2/Th1 balances were expressed by the ratio of IL- 4 and IFN- $\gamma$, and differences between IL-4/IFN- $\gamma$ ratios were analyzed by Mann-Whitney test with significance set at $\mathrm{p}<0.05$. The correlation between two continuous variables was analyzed by Spearman correlation with significance set at $\mathrm{p}<0.05$. For statistical analysis, the software StatView was used. 


\section{RESULTS}

Of the 18 patients with Chagas' disease assessed in this study, none presented cerebral impairment due to the infection. The parasitemia assay was evaluated by hemoculture and xenodiagnosis on 17 patients and these were positive in eight and negative in nine patients. According to CDC criteria, patients were classified as follows: B2 (12 patients), B3 (6 patients) and C3 (10 patients). Blood collection for parasitemia analysis, CD4 T lymphocyte counts and cytokine determination were taken simultaneously and during the asymptomatic period, to minimize the interference of other infections on the analyzed parameters.

The number of CD4 T lymphocytes in peripheral blood was significantly higher in patients with HIV/T. cruzi coinfection with a median number of 244 cells (from 84 - 442 cells $/ \mu m^{3}$ ), whereas in HIV patients a median of $88 \mathrm{cell} / \mathrm{ml}$ was detected (from 11 815 cells $/ \mu \mathrm{m}^{3}$ ) (Figure $1 \mathrm{a}$ ). When the number of CD4 T lymphocytes was analyzed in patients with Chagas' disease, according to parasitemia, the number of lymphocytes was higher in patients with $T$. cruzi parasitemia, although this difference was not significant (Figure 1b).

Serum levels of TNF- $\alpha$, IFN- $\gamma$, IL-1 $\beta$, IL- 4 and IL-10 were evaluated (Figure 2). No significant differences were observed in the levels of IL-1 or IL-10 between patients with HIV/T. cruzi coinfection and HIV patients. Levels of IL-4 were significantly higher in patients with HIV/T. cruzi, varying from zero to $6,220 \mathrm{pg} / \mathrm{ml}$ with a median of $864 \mathrm{pg} / \mathrm{ml}$, while in HIV patients, it varied from zero to $705 \mathrm{pg} / \mathrm{ml}$ with a median of zero. The levels of TNF- $\alpha$ were significantly higher in patients with HIV/T. cruzi, varying from zero to $13,300 \mathrm{pg} / \mathrm{ml}$ with a median of $280 \mathrm{pg} / \mathrm{ml}$, whereas in HIV patients, it varied from zero to

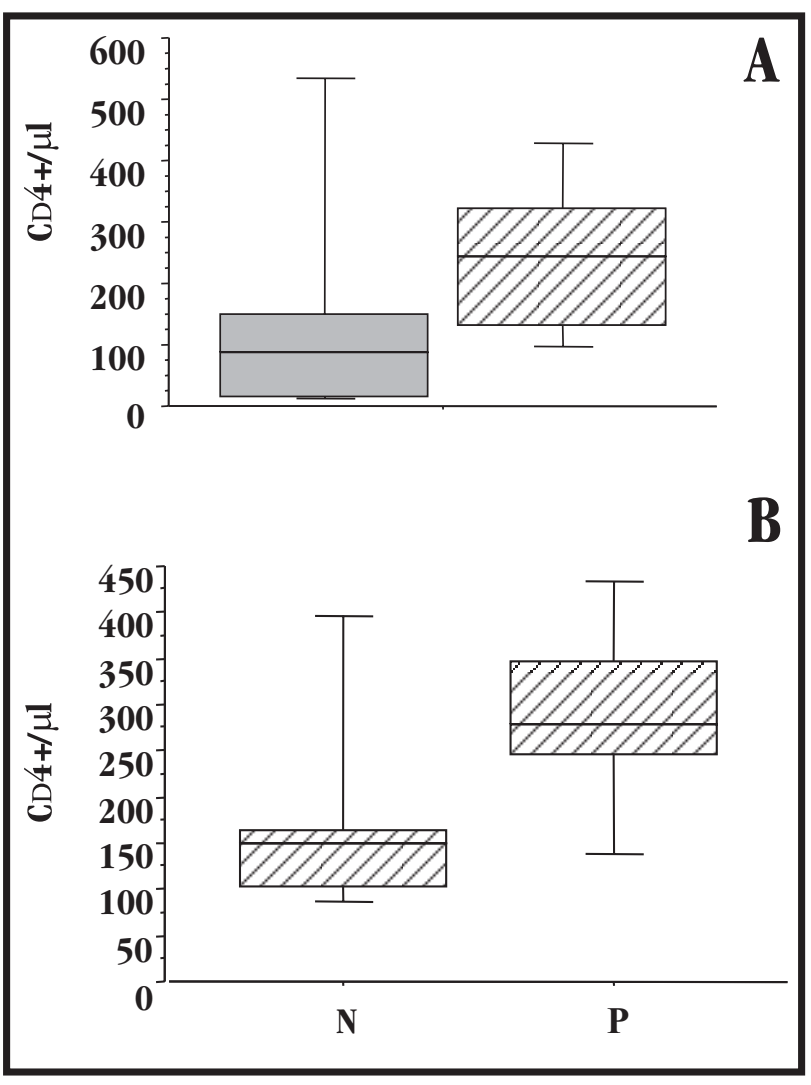

Figure 1 - Number of CD4+ T lymphocyte on blood from patients infected with human immunodeficiency virus (gray bars) and HIV/T. cruzi coinfection (hatched bars). CD4+T Tymphocyte were determined by flow cytometry using FITC conjugated $\mathrm{mAb}$ and expressed as the number of CD4+ cells per micro liter (A). Number of CD4+T lymphocytes was analyzed on the basis of parasitemia. N represent Chagas' disease patients with negative parasitemia $(n=9)$ and $P$ patients with positive parasitemia $(n=8)(B)$. Horizontal lines represent the median values, boxes represent the $25^{\text {th }}$ to $75^{\text {th }}$ percentiles and vertical lines the $10^{\text {th }}$ to $90^{\text {th }}$ percentiles.

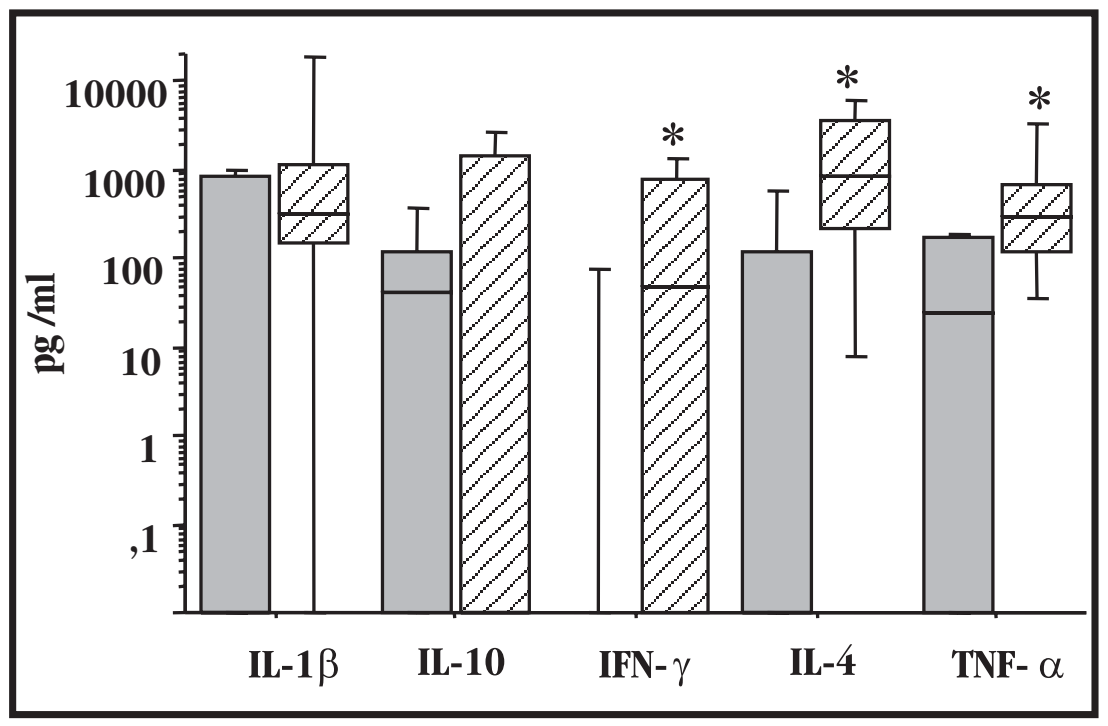

Figure 2 - Cytokine levels on serum from patients infected with HIV (gray bars, $n=10$ ) and HIV/Trypanosoma cruzi coinfection coinfection (hatched bars, $n=18$ ). Cytokines levels were determined in sera by ELISA and expressed in $\mathrm{pg} / \mathrm{ml}$. Horizontal lines represent the median values, boxes represent the $25^{\text {th }}$ to $75^{\text {th }}$ percentiles and vertical lines the $10^{\text {th }}$ to $90^{\text {th }}$ percentiles. Statistical significance between groups is indicated. * p $<0.05$ (Mann Whitney). 
$191 \mathrm{pg} / \mathrm{ml}$ with a median of $23 \mathrm{pg} / \mathrm{ml}$. Levels of IFN- $\gamma$ were also significantly higher in patients with HIV/ T cruzi varying from zero to $3,140 \mathrm{pg} / \mathrm{ml}$ with a median of $47 \mathrm{pg} / \mathrm{ml}$, while in HIV patients, it varied from zero to $124 \mathrm{pg} / \mathrm{ml}$ with a median of zero. No significant correlation was observed between CD4 lymphocyte counts and cytokines serum levels and no significant difference was observed when cytokines levels were analyzed on patients groups according to CDC class (data not shown).

The balance between Th1 and Th2 immune response can be analyzed by the ratio between the levels of IL- 4 and IFN- $\gamma$. This balance clearly favored a Th2 response in the group of patients with HIV/T. cruzi coinfection with a ratio that reached 856 with a median of 17.4 , while in HIV patients, this ratio reach 410 with a median of one (Figure 3a).

The balance favored Th2 cytokines in the group of patients with parasitemia, even though it did not show a statistically significant difference (Figure 3b).

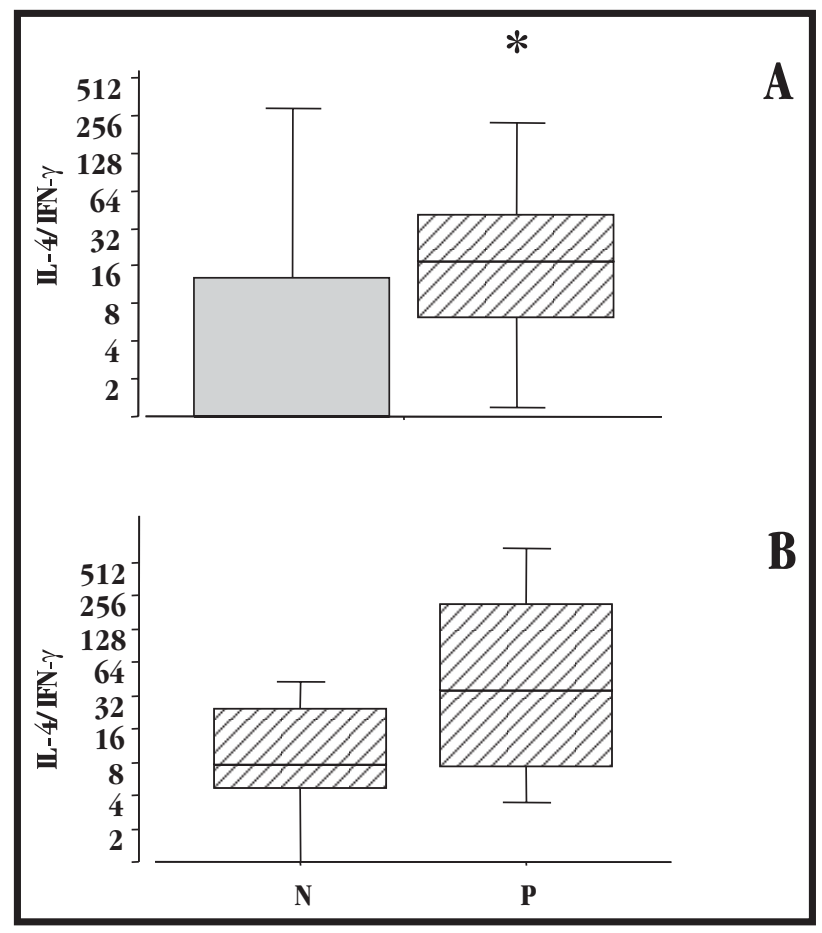

Figure 3 - Interleukin-4/interferon- $\gamma$ ratios in sera from patients infected with HIV (gray bars) and HIV/T. cruzi coinfection (hatched bars). Cytokine levels were determined in sera by ELISA and ratios were obtained dividing IL-4 levels by IFN- $\gamma$ levels for each subject (A). IL-4/IFN- $\gamma$ ratios were analyzed on the basis of parasitemia. $\mathrm{N}$ represents Chagas' disease patients with negative parasitemia and $\mathrm{P}$ patients with positive parasitemia (B). Horizontal lines represent the median values, boxes represent the $25^{\text {th }}$ to $75^{\text {th }}$ percentiles and vertical lines the $10^{\text {th }}$ to $90^{\text {th }}$ percentiles.

\section{DISCUSSION}

In Latin American countries, with the advance in the AIDS epidemic and the migration of Chagas' disease patients from rural areas to urban centers, there has been an increase in the risk of coinfection. The involvement of the immune system in patients infected by HIV, especially on Th1 immune responses, leads to a higher risk of $T$. cruzi infection reactivation. Little is known about the demands placed on the human immune mechanisms involved in resistance to $T$. cruzi, especially during the chronic phase of human infection. The impairment of immunity observed in patients infected by HIV provides an opportunity for investigation of the host-defense mechanism. In the course of $T$. cruzi HIV coinfection, various manifestations can be observed, ranging from severe reactivation of Chagas' disease, with central nerve system involvement, to no clinical manifestation of Chagas' disease with undetectable parasitemia ${ }^{20}$. In experimental $T$. cruzi infections, during the acute phase, the participation of Th1 immune responses seems to be fundamental for the control of the parasitemia $^{121}$, while antibodies seem to be involved in the control of the parasitemia in the chronic phase of the infection ${ }^{2}$.

Serum levels of cytokines have been used to evaluate the patterns of immune response in vivo in several human infections, including T. cruzi and HIV infection ${ }^{922}$. Although they reflect the reactions of the whole organism, factors such as hemodilution and plasmatic half-life should be considered. Analysis of these factors may be very informative, especially if it is considered that they reflect an in vivo phenomenon in which all cells that participate in the immune response are involved, and not just some of them.

Of the 18 patients coinfected with HIV/T. cruzi, none presented signs of infection reactivation with high parasitemia or central nervous system involvement. These patients presented numbers of CD4 T lymphocytes between 84 and 422 cells/ $\mu \mathrm{m}^{3}$, which were higher than patients with HIV, but below normal. Determination of serum cytokine levels demonstrated that patients with HIV/T. cruzi coinfection presented levels of IL- 4 , IFN- $\gamma$ and TNF- $\alpha$ significantly higher than those with HIV. These data suggest that patients have a response capacity, which leads to higher levels of IL-4 compared to IFN- $\gamma$, thus presenting a preferential activation of the Th2-like immune response. These findings are in accordance with the observation that Th1 immune response is preferentially affected in HIV patients, as Th1 lymphocytes are more susceptible to apoptosis than Th2 ${ }^{18}$. Impairment of the Th1 immune response is involved in susceptibility to several infections, especially by fungi, viruses, intracellular bacteria and even by protozoa, such as Leishmania sp. Other studies, analyzing levels of serum cytokines, have demonstrated that TNF- $\alpha$ levels are significantly higher in Chagas' disease patients compared to normal controls ${ }^{9}$, while other work has pointed to undetectable levels of TNF- $\alpha$ and IFN- $\gamma$ levels that did not differ from those of the controls ${ }^{22}$.

In this study, the impairment of the immune response, demonstrated by the reduction of the number of $\mathrm{CD} 4 \mathrm{~T}$ lymphocytes and by the Th1/Th2 imbalance, does not seem to be sufficient to lead to a recurrence of infection with CNS involvement. These results support the view that another immune effector mechanism, such as antibodies may be involved on the control of parasite growth in the chronic phase of Chagas' disease, as suggested by Brener and Gazzinelli². However, the Th1/Th2 balance seems to positively affect the parasitemia, since patients with positive parasitemia exhibit a predominance of Th2-like response. In this sense, it was observed that $T$. cruzi parasitemia was significantly more frequent among HIV infected patients ${ }^{20}$. These results confirm 
experimental data on the importance of Th1 immune response for controling the replication of $T$. cruzi ${ }^{1112}$.

The results presented here suggest that patients with HIV/ T. cruzi coinfection even with low levels of CD4 T lymphocytes and with a Th2-like bias response did not present reactivation of the infection, suggesting the participation of other immune mechanisms for parasite control. Furthermore, in group HIV/ T. cruzi coinfection no significant differences were observed in the number of CD4 T lymphocytes when analyzed according to parasitemia. Moreover, a tendency toward a predominance of Th2-like cytokines in patients with parasitemia would suggest the participation of the Th1/Th2 balance in the control of parasite replication in the chronic stages of Chagas' disease.

\section{REFERENCES}

1. Aliberti JCS, Souto JT, Marino APMP, Lanes-vieira J, Teixeira MM, Farber J, Gazzinelli RT, Silva JS. Modulation of chemokine production and inflammatory responses in Interferon- $\gamma$ and Tumor Necrosis Factor-R1Deficient Mice during Trypanosoma cruzi infection. American Journal of Pathology 158:1433-1440, 2001.

2. Brener Z, Gazzinelli RT. Immunological control of Trypanosoma cruzi infection and pathogenesis of Chagas' disease. International Archive of Allergy and Immunology 114:103-110, 1997

3. Chiari E, Dias JCP, Lana M, Chiari CA. Hemocultures for the parasitological diagnosis of human Chagas' disease. Revista da Sociedade Brasileira de Medicina Tropical 22:19-23, 1989.

4. Cohen JE, Tsai EC, Ginsberg HJ, Godes J. Pseudotumoral chagasic meningoencephalitis as the first manifestation of acquired immunodeficiency syndrome. Surgical Neurology 49:324-327,1998.

5. Del Castillo M, Mendoza G, Oviedo J, Perez Bianco RP, Anselmo AE, Silva M. AIDS and Chagas' disease with central nervous system tumor-like lesion. American Journal of Medicine 88:693-694, 1990

6. Ferreira MS. The acquired immunodeficiency syndrome and endemic disease in Brazil. Revista da Sociedade Brasileira de Medicina Tropical 29:531-535,1996.

7. Ferreira MS. Chagas' disease and immunosuppression. Memórias do Instituto Oswaldo Cruz 94:325-327, 1999.

8. Ferreira MS, Nishioka SA, Rocha A, Silva AM, Ferreira RG, Olivier W, Tostes Jr S. Acute fatal Trypanosoma cruzi meningoencephalitis in a human immunodeficiency virus-positive hemophilic patient. The American Journal of Tropical Medicine and Hygiene 45:723-727, 1991.

9. Ferreira RC, Ianni BM, Abel LCJ, Buck P, Mady C, Kalil J, Cunha-Neto E. Increased plasma levels of Tumor necrosis factor- $\alpha$ in asymptomatic/ "indeterminate" and Chagas' disease cardiomyopathy patients. Memórias do Instituto Oswaldo Cruz 98:704-711, 2003.

10. Gluckstein D, Ciferri F, Ruskin J. Chagas' disease: another cause of cerebral mass in the acquired immunodeficiency syndrome. American Journal of Medicine 92:301-302, 1992.

11. Holt DF, Eickhoff CS. Type 1 immunity provide optimal protection against both mucosal and systemic Trypanosoma cruzi challenges. Infection and Immunity 70:6715-6725, 2002.

12. Kumar S, Tarleton RL. Antigen-specific Th1 but not Th2 cells provide protection from lethal Trypanosoma cruzi infection in mice. Journal of Immunology 166:4596-4603, 2001.

13. Lages-Silva E, Ramirez LE, Silva-Vergara ML, Chiari E. Chagasic meningoencephalitis in a patient with acquired immunodeficiency syndrome: diagnosis, follow-up, and genetic characterization of Trypanosoma cruzi. Clinical Infectious Diseases 34:118-123, 2002.

14. Morgado MG, Barcellos C, Pina MF, Bastos FI. Human immunodeficiency virus/acquired immunodeficiency syndrome and tropical disease: a Brazilian perspective. Memórias do Instituto 0swaldo Cruz 95:145-151, 2000.

15. Pacheco RS, Ferreira MS, Machado MI, Brito CM, Pires MQ, Da-Cruz AM, Coutinho SG. Chagas' disease and coinfection: genotypic characterization of the Trypanosoma cruzi strain. Memórias do Instituto Oswaldo Cruz 93:165-169, 1998.

16. Palella Jr FJ, Delaney KM, Moorman AC, Loveless MO, Fuhrer J, Satt GA, Aschman DJ, Holmberg SD. Declining morbidity and mortality among patients with advanced human immunodeficiency virus infection. HIV outpatient study investigators. New England Journal of Medicine 338:853-860, 1998.

17. Preiser W, Cacopardo B, Nigro L, Braner J, Nunnari A, Doerr HW, Weber B. Immunological findings in HIV-Leishmania coinfection. Intervirology 39:285-288, 1996 .

18. Ramsdell F, Seaman MS, Miller RE, Kennedy MK, Lynch DH. Differential ability of Th1 and Th2 cells to express Fas ligant and to undergo activationinduced cell death. International Immunology 6:1545-1553, 1994.

19. Rocha A, Meneses AC, Silva MA, Ferreira MS, Nishioka SA, Burgarelli MK, Almeida E, Turcano Junior G, Metze K, Lopes ER. Pathology of patients with Chagas' disease and acquired immunodeficiency syndrome. The American Journal of Tropical Medicine and Hygiene 50: 261-268, 1994.

20. Sartori AM, J Neto E, Nunes EV, Braz LM, Caiaffa-Filho HH, Oliveira OC, Amato-Neto V, Shikanai-Yasuda MA. Trypanosoma cruzi parasitemia in chronic Chagas' disease: comparison between human immunodeficiency virus (HIV)-positive and HIV-negative patients. Journal of Infectious Disease $186: 872-875,2002$

21. Silva JS, Aliberti JCS, Martins GA, Souza MA, Souto JT, Pádua MA. The role of IL-12 in experimental Trypanosoma cruzi infection. Brazilian Journal of Medical and Biology Research 31:111-115,1998.

22. Ward LS, Guariento ME, Fernandes GA, Maciel RM. Serum cytokines in chronic Chagas' disease. Revista da Sociedade Brasileira de Medicina Tropical 32:285-289, 1999. 